\title{
ORGANIZAÇÕES DE APRENDIZAGEM: DISCIPLINAS PARA A GESTÃO COM PESSOAS NO SERVIÇO PÚBLICO
}

\author{
R. S. dos SANTOS ${ }^{1}$, A. B. C. de CASTRO ${ }^{2,4,}{ }^{*}$, M. da S. B. de FARIAS ${ }^{3}$, L. M. P. BRITO \\ ${ }^{1}$ Universidade Federal da Paraíba, ${ }^{2}$ Instituto Federal de Educação, Ciência e Tecnologia do Rio Grande do Norte, \\ ${ }^{3}$ Universidade Federal da Paraíba, ${ }^{4}$ Universidade Potiguar \\ brunnicastro@hotmail.com* \\ Submetido 07/10/2016 - Aceito 06/12/2017 \\ DOI: 10.15628/holos.2017.5171
}

\section{RESUMO}

O objetivo da pesquisa é analisar as atividades gerenciais desenvolvidas em uma instituição pública de educação, ciência e tecnologia à luz do modelo da Quinta Disciplina de aprendizagem organizacional proposto por Senge (2012). Trata-se de um estudo de caso de natureza descritiva, com abordagem qualitativa. Utilizou-se como aporte teórico o modelo da Quinta Disciplina. Os resultados sinalizaram que: as práticas dos gestores da instituição não estão plenamente de acordo com o modelo proposto, pois foram identificados desequilíbrios entre as cinco disciplinas, sobretudo, a quinta disciplina que apresentou o menor grau de concordância, e pode significar que, ao invés de uma visão persuasiva a organização tem uma visão tímida sobre as possibilidades de criação, aquisição, compartilhamento e transferência do conhecimento em seu interior, pois de forma consciente não consideram as partes como componentes de um todo, não encorajam que as pessoas tenham autoconfiança, que vão além das suas crenças e dos seus impulsos, não possibilitam que seus integrantes compartilhem seus objetivos e trabalhem em equipe em torno de projetos inovadores voltados para a sociedade.

PALAVRAS-CHAVE: Organização que Aprende; Organização pública; Gestão; A quinta disciplina; Educação, Ciência e Tecnologia.

\section{LEARNING ORGANIZATIONS: subjects for management with people in the public service}

\begin{abstract}
The objective of the research is to analyze the managerial activities developed in a public institution of education, science and technology by means of the model of the Fifth Discipline of organizational learning proposed by Senge (2012). This is a case study of a descriptive nature, with a qualitative approach. The model of the Fifth Discipline was used as theoretical contribution. The results showed that: the practices of the managers of the institution are not fully in agreement with the proposed model, because imbalances between the five disciplines were identified,
\end{abstract}

especially the fifth discipline that presented the least degree of agreement, and could mean that, instead from a persuasive view, the organization has a timid view of the possibilities of creating, acquiring, sharing, and transferring knowledge within, for they consciously do not consider the parts as components of a whole, they do not encourage people to have self-confidence, which go beyond their beliefs and their impulses, do not allow their members to share their goals and work in teams around innovative projects geared towards society.

KEYWORDS: Learning organization; Public organization; Management; The fifth discipline; Education, Science and Technology. 


\section{INTRODUÇÃO}

O termo Learning Organization ou Organização que Aprende (OA) é bem mais difundido hoje do que há mais de vinte anos quando começou a ser popularizado com a primeira edição do livro "A Quinta Disciplina", de Peter Senge.

Senge popularizou o conceito com uma teoria fundamentada em cinco disciplinas, que quando seguidas contribuíam para qualquer organização se transformar numa OA, sendo: (1) domínio pessoal; (2) modelos mentais; (3) visão compartilhada; (4) aprendizagem em equipe e (5) pensamento sistêmico.

As cinco disciplinas são todas inter-relacionadas e com foco na relação do indivíduo com o mundo que o cerca, incluindo-se as organizações. "Essas disciplinas representam abordagens (teorias e métodos) para desenvolver as três capacidades centrais da aprendizagem: estimular as aspirações, desenvolver conversas reflexivas e entender a complexidade". (Senge, 2012, p. 17).

O resultado da publicação de Peter Senge e de outras publicações da época foi a criação de uma visão persuasiva das organizações composta por trabalhadores qualificados para criar, adquirir, compartilhar e transferir conhecimento (Garvin, Edmondson \& Gino, 2008), num ambiente altamente tecnológico e competitivo.

Entretanto, muitas organizações através de seus gestores ainda não sabem que precisam compreender o que é uma $\mathrm{OA}$, pois talvez esse seja o maior problema por eles enfrentado quando o assunto é "aprender": "não entender o que é a aprendizagem e não saber como realizá-la." (Argyris, 1991, p. 4).

Além disso, segundo Senge (2012, p. 21), em um mundo em constantes mudanças se faz cada vez mais necessária a adoção de OA, devido a complexidade do macro e do micro ambiente, já que

[...] estão criando mais redes, o que enfraquece as hierarquias tradicionais da administração e potencialmente abre novos espaços para o aprendizado, a inovação e a adaptação constante. Por outro lado, os defeitos do sistema de gerenciamento tradicional mantêm muitas organizações num estado perpétuo de apagar incêndios, com pouco tempo ou energia para a inovação. Esse ritmo louco e esse caos também solapam a construção de culturas de administração baseadas em valores e abrem as portas para golpes de oportunistas em busca do poder individual ou de dinheiro.

As organizações públicas seguem esse mesmo contexto, pois estudos publicados sobre o tema ainda apontam os desafios para se entender o modelo de OA são: vencer a letargia conceitual sobre o modelo de modo que as organizações possam se apoderar de seus benefícios; considerar as experiências, a criatividade e as ideias dos trabalhadores; criar infraestrutura física e digital para facilitar o armazenamento do conhecimento que poderá subsidiar o processo de tomada de decisão; iniciar um esforço educacional de criação de uma cultura aprendente; a ressignificação da gestão de pessoas e o ajuste do sistema de planejamento de modo que seja facilitado o processo de criação, o compartilhamento e a disseminação do conhecimento como um costume social das pessoas na organização; criar novos cargos como o de gestor do conhecimento, ativista do conhecimento ou gerente do conhecimento; recompensar os trabalhadores conforme a capacidade de contribuição e lealdade dos trabalhadores; formalizar a gestão do conhecimento para que as práticas de aprendizagem desenvolvidas façam parte da estratégia organizacional; vencer a burocratização; vencer as estruturas acomodadas em suas zonas de conforto; gestores que ainda permanecem com atitudes imediatistas que apenas resolvem o problema momentaneamente; mudança no foco das organizações de especialista funcionalista para flexível; maior orientação para controlar em vez de ensinar; recompensam o 
desempenho das pessoas com base em obediência a padrões determinados e não pelo desejo que elas possuem em aprender, entre outros. (Brito, 2005; Costa, Vasconcelos \& Candido, 2009; Silva, Sicsú \& Carvalho, 2009; Dihl, Holanda \& Francisco, 2010; Oliveira, 2011; Strauhs et al., 2012; Bolson, 2012; Galvão, 2012; Batista, 2012; Brito, Oliveira \& Castro, 2012; Senge, 2012; Vasconcelos, 2014; Gonzaga, 2014; Castro, Brito \& Varela, 2014; Santos, 2014; Castro, Brito \& Santos, 2015; Marques, 2015; Castro \& Brito, 2016).

Além disso, em se tratando de um estudo desenvolvido em uma organização de educação, ciência e tecnologia, Lück (2000, p. 2) coloca que: o que se observa ainda, muitas vezes no ambiente escolar é que:

\footnotetext{
[...] não tão raramente, gestores e profissionais em geral que se lamentam de estarem trabalhando como quem está "apagando incêndios", isto é, de estarem "sempre correndo atrás do prejuízo" e sendo conduzidos pelas situações variadas do cotidiano, pelas demandas inesperadas, tendo que responder rapidamente a elas e de tal forma que "não têm tempo para pensar, quanto menos para planejar". Esta forma de administrar por crise é estimulada e orientada por descobertas ocasionais e espontâneas, de caráter imediatista, por uma visão de senso comum e reativa da realidade e, portanto, limitada em seu alcance, muito influenciada pela tendência de se agir por tentativas e erros. Nesse caso, os acontecimentos determinam a ação de dirigentes escolares, em vez de, como seria próprio, os dirigentes, por meio de uma ação competente influenciarem os acontecimentos e a realidade.
}

Diante do exposto questiona-se: em uma instituição pública de educação, seus gestores conhecem e executam as práticas propostas pela aprendizagem organizacional para resolução dos problemas do dia a dia? Qual a contribuição que o modelo da Quinta Disciplina - da AO, pode prestar para os gestores de organizações educativas?

Para responder às questões levantadas, tem-se como objetivo geral da pesquisa: verificar como as atividades gerenciais são desenvolvidas na instituição pesquisada e como elas se aproximam do modelo da Quinta Disciplina de aprendizagem organizacional proposto por Senge (2012). Como objetivos específicos têm-se: caracterizar as práticas gerenciais desenvolvidas, verificar se os gestores executam as atividades próprias da aprendizagem organizacional a partir do modelo da Quinta Disciplina, e identificar as dificuldades dos gestores na aplicação do modelo da OA.

O interesse pelo tema surgiu com a identificação entre os autores com suas trajetórias profissionais, pois atuam em organizações educativas (de aprendizagem), e trajetórias educacionais, pois todos desenvolveram estudos e/ou participam de grupos de pesquisa em universidades e institutos federais, que estudam sobre os novos modelos de gestão das organizações. Além disso, a escolha da instituição pesquisada partiu da percepção de características de gestão participativa e democrática, aberta à comunidade, com políticas de incentivo a aprendizagem instituídas, e disponibilidade das informações concernentes à gestão devidamente arquivados e de fácil acesso.

A instituição pesquisada é de educação formal e tem como função social promover a educação científico-tecnológico-humanística visando à formação integral do profissional-cidadão, através da educação profissional de nível médio, cursos de formação inicial e continuada, realizar pesquisas aplicadas, desenvolver atividades de extensão à sociedade de acordo com os princípios e finalidades da educação profissional e tecnológica, e ministrar em nível de educação superior e pós-graduação. (Dantas \& Costa, 2012).

Trata-se de um estudo de caso, de natureza descritiva com abordagem qualitativa. A pesquisa teve como aporte teórico o modelo da Quinta Disciplina desenvolvido por Senge (2012). 


\title{
2 FUNDAMENTAÇÃO: as organizações que aprendem
}

Existem muitos estudos acerca da temática aprendizagem, porém, não existe um consenso na literatura no que se refere à definição de uma $\mathrm{OA}$, pois os conceitos, assim como seus modelos complementares - Gestão por Competência e Gestão do Conhecimento, buscaram postulados, premissas e metáforas de outras ciências. No caso, empréstimos relevantes são realizados em vários campos do conhecimento, inclusive da Psicologia do Trabalho e das Organizações, da Educação, da Sociologia, da Economia, da Ciência da Informação, da Administração, entre outros. (McClelland, 1973; Boyatizis, 1982; Drucker, 1990; Hamel \& Prahalad, 1995; Senge, 1995; Fleury, 1995; Nonaka \& Takeuchi, 1997; Stewart, 1998; Davenport \& Prusak, 1998; Sveiby, 1998; Frigotto, 1999; Zarifian, 2001; Ramos, 2001; Perrenoud et al., 2002; Dutra, 2002; 2004; Bukowitz \& Williams, 2002; Choo, 2003; Le Boterf, 2003; Quinn, 2003; Oliveira, 2004; Ruas, Antonello \& Boff, 2005; Brito, 2005; Terra, 2005; Antonello \& Godoy, 2011).

Para Boxenbaum e Rouleau (2011) é difícil dizer se os estudos de aprendizagem se enquadram como evolutivos, diferenciadores ou como um processo de colagem entre várias teorias. Em boa medida, os estudos desse campo buscam complementar lacunas e desenvolver construtos, num processo de desenvolvimento, de ampliação do campo de conhecimento - tipo evolutivo (Nogueira \& Odelius, 2015), e que não para de ser revisado, pois existe espaço de consolidação e desenvolvimento para os conceitos e pressupostos de aprendizagem em organizações, principalmente para o século XXI, considerado como o século das redes sociais e da informação democratizada.

Entre os conceitos em construção, tem-se que OA, conforme colocado por Nogueira e Odelius (2015), por exemplo,

\begin{abstract}
[...] se relaciona a organizações aptas a adquirir conhecimentos por meio da comparação de experiências pessoais com as de outras organizações; instituições nas quais as pessoas se voltam para a aprendizagem coletiva, comprometidas com resultados que sejam motivadores; organizações capazes de adquirir, criar, produzir novos insights, transferir conhecimentos e modificar o comportamento de seus membros. (p. 14).
\end{abstract}

Para Tsang (1997), a organização que aprende tem seu foco na ação e no ajuste de ferramentas metodológicas específicas para o diagnóstico e avaliação que permitem identificar, promover e avaliar a qualidade dos processos de aprendizagem.

Teodoro (2005) caracterizam as organizações de aprendizagem baseado no estudo de vários autores, conforme o Quadro abaixo.

\begin{tabular}{|c|l|}
\hline Itens & \multicolumn{1}{|c|}{ Organização que aprende } \\
\hline Público alvo & Gestores \\
\hline Desenvolvimento & $\begin{array}{l}\text { Desenvolvidas por pesquisadores e consultores que estão orientados para a transformação } \\
\text { organizacional }\end{array}$ \\
\hline Finalidade & Mudar e prescrever \\
\hline Natureza & Natureza mais descritiva \\
\hline Foco & $\begin{array}{l}\text { Questionamentos do tipo “o que", descrevendo os sistemas, características e princípios da } \\
\text { organização que aprende como uma entidade coletiva }\end{array}$ \\
\hline Objetivo & $\begin{array}{l}\text { Ajuste de ferramentas metodológicas específicas para o diagnóstico e avaliação que permitem } \\
\text { identificar e avaliar a qualidade dos processos de aprendizagem }\end{array}$ \\
\hline Organização & Aprendizado através da organização como um sistema integrado \\
\hline
\end{tabular}

Quadro 2 - Características da organização que aprende. Fonte: Adaptado de Teodoro (2005). 
Peddler, Boydell e Burgoyne (1998) ainda definem como características das organizações que aprendem: apresentar um clima que estimula os membros a questionar, a aprender e a desenvolver seu potencial, a agir em consonância com uma cultura de aprendizagem que envolve consumidores, fornecedores e outros grupos de interesse, a assumir o desenvolvimento de pessoas como central para seu negócio, e defender a transformação e a mudança como processos contínuos.

Para Senge (2012, p. 28) organizações que aprendem são:

Organizações nas quais as pessoas expandem continuamente a sua capacidade de criar os resultados que realmente desejam, onde se estimulam padrões de pensamento novos e abrangentes, onde a aspiração coletiva ganha liberdade e onde as pessoas aprendem continuamente a aprender juntas.

O autor coloca que faz-se necessário resgatar a capacidade de ver o mundo como um sistema de forças entrelaçadas e relacionadas entre si. Ao fazer isso as organizações estarão em condições de desenvolver a aprendizagem, na qual as pessoas se colocarão objetivos mais altos, aprenderão a criar os resultados desejados e a usar novos e elevados padrões de raciocínio, em fim, onde as pessoas poderão aprender em grupo e gerar a inovação. (Senge, 2012).

Portanto, a OA tem como objetivo precípuo aproveitar ao máximo as contribuições individuais de cada trabalhador a fim de que os processos sejam revistos do ponto de vista da aprendizagem.

Em seguida tem-se a construção teórica sobre as cinco disciplinas de Senge (2012) para melhor caracterização de uma AO.

\section{DISCIPLINAS DA ORGANIZAÇÃO QUE APRENDE}

Segundo Senge (2012), "disciplina” nesse contexto, significa um conjunto de técnicas que devem ser estudadas e dominadas para serem postas em prática. $\mathrm{O}$ autor menciona primeiro a disciplina do Pensamento Sistêmico, pois ela é a principal, a que une todas as outras. Desse modo, decidiu-se também iniciar pela Quinta Disciplina, para em seguida tratar das demais.

\subsection{A Quinta Disciplina: Pensamento/Raciocínio Sistêmico}

De acordo com Senge (2012) a quinta disciplina une todas as demais. Essa disciplina é considerada a pedra fundamental da organização que aprende, pois devido a complexidade do mercado, é muito mais difícil integrar novos instrumentos, atividades e procedimentos, do que aplicá-los separadamente.

O Pensamento Sistêmico tem como objetivo principal possibilitar a visão do todo e não apenas as partes isoladas. Seria considerar que tudo que for realizado na organização não poderá ser feito, sem antes levar em consideração as consequências, pois segundo essa disciplina, cada um afeta o trabalho do outro, pois a organização é composta por partes que se unem como sistemas. Significa "[...] deixar o presente para se dedicar ao futuro." (Senge, 2012, p. 108).

Ao apresentar o Pensamento Sistêmico, Senge (2012) descreve onze leis que funcionam, na visão do autor, como conselhos aos administradores, que devem considerá-los para detectar mais eficazmente os erros e analisá-los de forma correta, sendo: os problemas de hoje vêm das soluções de ontem; quanto mais você empurra, mais o sistema empurra de volta; o comportamento melhora antes de piorar; a saída mais fácil normalmente nos leva de volta para dentro; a cura pode ser pior do que a doença; mais rápido significa mais devagar; causa e efeito não estão próximos no tempo e no espaço; pequenas mudanças podem produzir grandes 
resultados - mas, frequentemente, as áreas de maior alavancagem são as menos óbvias; você pode assobiar e chupar cana - mas não ao mesmo tempo; dividir um elefante ao meio não produz dois pequenos elefantes; e, não existem culpados.

A intenção de Senge (2012) com as Leis da Quinta Disciplina é de sensibilizar os gestores de que é preciso "uma mudança de mentalidade" para que todas as decisões sejam bem planejadas, para que o todo seja analisado, para que considerem situações e consequências. Essas leis são apenas alguns dos pontos que devem ser observados para que seja mais fácil pensar de forma sistêmica.

Senge (2012) menciona que a humanidade talvez tenha a capacidade de gerar mais informações do que se pode absorver, de proporcionar uma interdependência muito maior do que o homem pode gerenciar e de acelerar as mudanças com uma velocidade muito maior do que o homem pode acompanhar, e esse é um dos medos que assolam as organizações (Bukowitz \& Williams, 2002; Angeloni et al., 2008; Takarashi \& Fischer, 2009; Corley \& Gioia, 2011; Nogueira \& Odelius, 2015), pois a impossibilidade de lidar com a complexidade, a incerteza e as constantes mudanças, criam situações concretas de medo, ansiedade e ameaça à auto-imagem das organizações. Algumas organizações desenvolvem o pensamento de que o futuro e a criação de novos conhecimentos são processos que implicam altos riscos e altos investimentos etc.

Nesse sentido, percebe-se que um mundo complexo exige que as pessoas se preocupem em analisar todo o contexto em que os problemas estão inseridos a fim de que possam desenvolver soluções realmente eficazes, com intuito de que a organização seja uma organização que aprende, quebrando o paradigma do medo da mudança.

\subsection{Domínio Pessoal}

Para que as organizações aprendam, é necessário que antes os indivíduos aprendam. Apesar da aprendizagem individual não garantir a aprendizagem organizacional, sem ela, a aprendizagem organizacional não ocorre. Senge define Domínio Pessoal como "a expressão que eu e meus colegas usamos para a disciplina do crescimento e do aprendizado pessoais".

De acordo com Senge (2012, p. 179):

O domínio pessoal ou capacidade individual é a aptidão fundamental para que uma pessoa possa ampliar seus próprios valores e não se deixar levar pelas circunstâncias. Para tanto, são primordiais, uma percepção clara da realidade e a firmeza dos próprios propósitos. É o conhecimento de si mesmo, que vai muito além das habilidades e da competência, apesar de se basear nelas. Vai além da revelação e da abertura espiritual, embora exija crescimento espiritual.

Para que o domínio pessoal se torne uma disciplina ele deve incorporar dois movimentos/princípios subjacentes: devemos esclarecer continuamente o que é importante para nós, e devemos aprender continuamente a enxergar com mais clareza a realidade do momento.

Aprendemos a esclarecer e aprofundar continuamente nosso objetivo pessoal, a concentrar nossas energias, a desenvolver a paciência, e utilizar a criatividade, ou seja, viver a vida de um ponto de vista criativo, em contraposição a um reativo, assim a justaposição do nosso objetivo (o que desejamos) com uma imagem clara da realidade (onde estamos em relação ao que desejamos) gera o que o Senge (2012) chamou de "tensão criativa".

A essência do domínio pessoal está em aprender a gerar e manter tensão criativa em nossas vidas.

Pessoas com alto nível de domínio pessoal possuem várias características em comum: tem um sentido especial de vida que vai além dos objetivos e metas ocasionais; para elas, a realidade 
do momento é um aliado, e não um inimigo; elas aprenderam a identificar e trabalhar com as forças de mudanças ao invés de resistir a elas; são profundamente inquisitivas, procuram sempre ver a realidade com maior clareza; sentem-se ligadas ao próximo e à vida em si; todavia, não abrem mão da sua individualidade; se sentem parte de um processo criativo maior, no qual podem influir mas que não podem controlar unilateralmente.

Entretanto, de acordo com Senge (2012), apesar de parecer o contrário, mesmo as pessoas que possuem um alto nível de domínio pessoal vivem em estado de aprendizagem contínua. Elas nunca "chegam lá". Segundo o autor, não se pode interpretar o termo "domínio pessoal" de forma literal, não se possui domínio pessoal, "é um processo, uma disciplina para uma vida inteira".

Além disso, pode surgir o seguinte questionamento: "por que seria interessante o domínio pessoal na organização?" Nesse sentido Choo (2003); Brito (2005); Schlesinger et al. (2008); Tavares (2010); Brito et al. (2012); Strauhs et al. (2012) colocam que: o desenvolvimento pleno das pessoas através das competências, está no mesmo plano que o sucesso financeiro, pois o conjunto de competências individuais é que formas as core competências organizacionais para enfrentar a incerteza do ambiente mercadológico.

Por isso, tornou-se consenso de que qualquer profissional que queira garantir sua sobrevivência no mercado deve apegar-se à ideia de atualização constante na busca das competências requeridas pelas organizações. (Roggero, 2003).

Por outro lado, mobiliza as organizações, que requerem de seus trabalhadores qualificações mais amplas, habilidades mais diversificadas, aprendizagem continuada e habilidades do saber fazer, e para isso fornecem condições facilitadoras de acesso à aprendizagem. (Schlesinger et al., 2008; Takahashi \& Fischer, 2009; Brito et al., 2012; Batista, 2012; Strauhs et al., 2012; Castro et al., 2014; Marques, 2015).

Drucker (1990) atribuiu às pessoas que buscam o conhecimento, o título de Trabalhadores do Conhecimento, pois são executivos do conhecimento que sabem alocar o conhecimento para uso produtivo, da mesma forma que o capitalista sabe alocar o capital para uso produtivo.

Desse modo, para começar a trabalhar uma noção de domínio pessoal o interessante é tratá-la como uma disciplina, ou seja, como uma série de práticas e princípios que devem ser aplicados para que sejam úteis. Nesse contexto, algumas práticas e princípios são citados e comentados por Senge (2012), pois são considerados importantes para a preparação, inserção e expansão contínua do domínio pessoal, sendo: a visão pessoal é particular de cada um, vem de dentro da pessoa; não se pode entender a verdadeira visão sem considerar a ideia de propósito; a tensão criativa é a lacuna existente entre a visão e a realidade atual; a tensão criativa é o princípio base do domínio pessoal, que integra os demais elementos da disciplina; dominar a tensão criativa demonstra capacidade de perseverança e paciência; e, no conflito estrutural, até mesmo pessoas mais bem-sucedidas, alimentam profundas crenças contrárias ao seu domínio pessoal.

\subsection{Modelos Mentais}

Os Modelos Mentais são ideias que estão profundamente enraizadas, são paradigmas e por isso, influenciam o modo como as pessoas enxergam o mundo e também suas atitudes.

Nesse sentido, é interessante mencionar que a disciplina do domínio dos modelos mentais (trazer à tona, testar e aperfeiçoar nossas imagens internas acerca do funcionamento do mundo) promete trazer uma considerável mudança para a criação das organizações que aprendem. Para Senge (2012), os modelos mentais que cada um possui são determinantes não apenas para a forma de compreender o mundo, mas também a forma de agir de cada pessoa. 
De acordo com Argyris (1991), embora não se comportem [sempre] de forma coerente com suas teorias esposadas [aquilo que dizem], as pessoas comportam-se de forma coerente com suas teorias-em-uso [seus modelos mentais].

Mas, por que os modelos mentais afetam tanto o que fazemos? Acerca desse questionamento, Senge (2012) coloca que: como as pessoas são diferentes umas das outras, mesmo dois indivíduos vendo a mesma situação, eles podem descrever de forma diferente, pois como os modelos mentais são diferentes, eles veem detalhes diferentes e fazem interpretações distintas.

Uma das razões da disciplina Modelos Mentais é que a meta é não haver consenso na organização. A existência de modelos mentais múltiplos proporciona múltiplas perspectivas, e isso ajuda a criar o que Nonaka e Takeuchi (1997) chamaram de "Flutuação e Caos Criativo", que se refere "a uma interrupção de nosso estado de ser habitual e confortável. Quando enfrentamos um colapso, temos a oportunidade reconsiderar nosso pensamento e perspectivas fundamentais" (p. 89). Em suma, Boog (2004) coloca que a mudança pode precipitar o caos criativo, que induz e fortalece o compromisso subjetivo dos indivíduos com a organização. Esse fortalecimento do compromisso se dá através do Domínio Pessoal.

O importante é que todos os modelos mentais existentes sejam analisados e testados em situações que possam surgir, para que seja escolhido o melhor modelo mental para a resolução dos problemas organizacionais. Nesse caso, quando a resolução do problema é atingido, leva-se ao consenso.

\subsection{Visão Compartilhada}

A visão compartilhada se trata de um sentimento de coletividade que permeia e dá coerência para todas as atividades. Assim como os objetivos pessoais são quadros ou imagens que as pessoas carregam nas suas mentes e corações, o mesmo acontece com as imagens do objetivo comum que as pessoas de uma mesma organização carregam.

A visão compartilhada, ou objetivo comum, é vital para a organização em contínuo aprendizado, por que proporciona o foco e a energia para a aprendizagem. Trata-se da disseminação do conhecimento tácito, que é o conhecimento pessoal incorporado à experiências de trabalho, às habilidades, expertises, envolve fatores intangíveis como crenças, valores, objetivos pessoais, conclusões, insights, feeling, palpites subjetivos, emoções, ideais, competências, raciocínio, modelos mentais, conclusões, gerações de ideias, opiniões, intuição, criatividade etc. (Nonaka \& Takeuchi, 1997; Figueiredo, 2005; Brito, 2005, 2008; Angeloni et al., 2008; King, 2009; Tavares, 2010; Scoot, 2011).

O conhecimento tácito é criado e compartilhado no bebedouro, por exemplo, e se dissemina quando as pessoas se encontram e dialogam, ou se empreenderem um esforço sistemático para descobri-lo e torná-lo explícito. (Stewart, 1998). Por isso, é importante que as organizações criem condições facilitadoras para a criação e socialização do conhecimento tácito. No contexto organizacional o importante é que "o conhecimento tácito precisa se tornar explícito; o que não foi dito, precisa ser dito em voz alta; caso contrário, não pode ser examinado, aperfeiçoado ou compartilhado." (Stewart, 1998, p.66). Pois, "grande parte do capital intelectual consiste em conhecimento tácito, não expresso - como, por exemplo, o conhecimento especializado e os relacionamentos que um vendedor constrói ao longo de anos de trabalho em um território." (Stewart, 1998, p.62).

O reconhecimento do conhecimento tácito é importante, pois dá origem a uma nova perspectiva da organização, não mais de simplesmente uma máquina de processamento de informações, característica do período clássico da administração; mas de um organismo vivo, 
capaz de se aperfeiçoar para se adaptar, utilizar de sua experiência para gerar novas expertises organizacionais e, portanto, inovar continuamente a partir de uma visão compartilhada globalmente pelos trabalhadores.

A Visão Compartilhada seria a existência de um interesse comum nas pessoas que trabalham em uma instituição. Nesse ponto, a figura do líder é essencial, pois ele pode orientar as pessoas, estimulá-las a sentirem vontade de possuir uma visão conjunta, baseada no todo da organização.

É o que muitos autores chamam de "papéis de gestão do conhecimento", pois são gestores que ajudam os trabalhadores a compartilhar o que eles sabem que sabem, pois uma pessoa pode saber muito sobre determinada área, mas a menos que escreva sobre isso, crie uma apresentação, monitore ou exponha, o conhecimento beneficia somente uma pessoa, pois a raiz da aprendizagem organizacional é a noção de que as organizações, através de seus membros, devem ser capazes de adquirir novos conhecimentos e agir sobre eles, renovando assim, o contexto do qual a aprendizagem futura brotará. (Skerlavaj, Song \& Lee, 2010; Scoot, 2011; Rakhsh \& Ahmadi, 2011; Shehzad \& Khan, 2013; Wahyuningsih \& Astuti, 2013).

Faz-se interessante mencionar que a visão compartilhada não é uma ideia, apesar de poder ser inspirada por uma; mas uma força existente no coração das pessoas que possui um poder impressionante. Quando essa ideia evolui ao passo que começa a ser apoiada por mais de uma pessoa, a abstração cede lugar para o palpável, ou seja, atua como se de fato existisse. As visões compartilhadas são imagens que as pessoas possuem em uma instituição. "Uma visão é realmente compartilhada quando você e eu temos a mesma imagem e assumimos o comprometimento mútuo de manter essa visão, não só individualmente, mas em conjunto" (Senge, 2012, p. 255).

Nesse sentido, percebe-se que ter uma visão compartilhada significa que o objetivo institucional assume o mesmo grau de importância entre as pessoas e existe um comprometimento em cumpri-lo.

\subsection{Aprendizagem em Equipe}

A Aprendizagem em Equipe "é o processo de alinhamento e desenvolvimento da capacidade da equipe de criar os resultados que seus membros realmente desejam" (Senge, 2012, p. 288). Ela se desenvolve a partir da criação de um objetivo comum e também do domínio pessoal.

Senge (2012) adverte que a aprendizagem em equipe não se trata da existência de amizades entre o grupo, mas de um relacionamento que torna a equipe importante e muito especial. O autor cita o exemplo do time "Boston Celtics de Russel", que venceu 11 mundiais em 13 anos, pois trabalharam sempre em equipe para apresentar a palavra "alinhamento", que significa um grupo de pessoas atuando como um todo. Em contrapartida, afirma que o desperdício de energia demonstra uma equipe relativamente desalinhada. Conforme a equipe se torna mais alinhada, acontece uma unidade de direção e com isso, as energias dos indivíduos se harmonizam.

É importante destacar que não ocorre um sacrifício das visões pessoas em prol do grupo, é o contrário, a visão compartilhada é que é tida como uma extensão das visões pessoais individuais. Nesse sentido, existe um propósito comum, e surge uma compreensão de como complementar os esforços dos outros. Senge (2012, p.287) acrescenta ainda que é preciso a existência do alinhamento para que o empowerment individual ocasione o empowerment de toda a instituição. 
O aprendizado em grupo tem três dimensões, sendo: é necessário analisar com discernimento as questões complexas, existe a necessidade de se tomar ações inovadoras e coordenadas e, existe a influência dos membros de um grupo sobre outros grupos.

Apesar de envolver habilidades individuais e áreas de conhecimento, o aprendizado em grupo é uma disciplina coletiva. Essa disciplina requer a prática do diálogo (o grupo analisa questões complexas sob diferentes pontos de vista, comunicando suas ideias livremente) e da discussão (o assunto de interesse comum pode ser analisado e dissecado sob os diferentes pontos de vista daqueles que dele participam).

O importante é que uma equipe de aprendizagem saiba se movimentar entre o diálogo e a discussão, passando de um para os outros sempre que necessário, e esse processo pode ser mediado pelos papeis de gestão do conhecimento citados anteriormente.

As organizações precisam prover espaços e estratégias para que as pessoas leais à organização se sintam a vontade para contribuir com o que sabem, evitando-se que os trabalhadores desenvolvam estratégias de defesa, como o "não contribuir". É o que Choo (2003), chamou de "condições capacitadoras", que podem representar a adoção de práticas voltadas à criação do conhecimento pelas organizações, a partir do conhecimento que reside nas pessoas. Meister (1999); Brito (2005); Schlesinger et al. (2008); Strauhs et al., citam como exemplo de práticas: educação corporativa, portais corporativos do conhecimento, memória organizacional, mapas de conhecimento, e-business, benchmarking, comunidades de práticas, sistemas de informação (intranet, workflow, groupware, inteligência artificial, business intelligence, innovation supporte tools etc.), gestão de pessoas alinhada à criação do conhecimento (gestão por competências), gestão de conversas e ideias, criação de cargos de gestor do conhecimento, gestão de documentos etc.

Essas condições capacitadoras apresentadas pelos autores permitem que as organizações tenham ideia de como fomentar a criação e disseminação do conhecimento, a fim de manter a vantagem competitiva e até mesmo servir de modelo para diretores e gerentes de organizações, sejam públicas ou privadas.

Nas seções seguintes, foram abordados os procedimentos metodológicos e os resultados encontrados na pesquisa a partir dos objetos propostos.

\section{METODOLOGIA DA PESQUISA}

A presente pesquisa tem como aporte teórico o modelo da Quinta Disciplina desenvolvido por Senge (2012) e se trata de um estudo de caso (Yin, 2010) de abordagem qualitativa (Vergara, 2007).

Segundo Godoy (1995, p. 26):

Ainda que os estudos de caso sejam, em essência, pesquisa de caráter qualitativo, podem comportar dados quantitativos para aclarar algum aspecto da questão investigada. É importante ressaltar que, quando há análise quantitativa, geralmente o tratamento estatístico não é sofisticado.

A coleta dos dados se deu mediante questionário em que se buscou aferir as capacidades centrais da aprendizagem (Quadro 1), entrevista semiestrutura e pesquisa documental. Com relação aos objetivos, a presente pesquisa classifica-se como descritiva (Kauark, Manhaes \& Souza, 2010). 
A escolha dos gestores como público-alvo se deu, pois são eles os possíveis responsáveis por disseminar uma cultura aprendente e conhecem o fluxo do conhecimento dentro da instituição.

Realizou-se um senso com os gestores investidos em Cargos de Direção (geral, acadêmica e de administração), no total de três respondentes e 14 gestores em nível de Coordenação (TI; Gestão de Pessoas; Comunicação Social e Eventos; Laboratórios; Secretaria Acadêmica; Apoio Acadêmico; Administração Escolar; Multimeios; Pesquisa e Inovação; Extensão; Atividades Estudantis; Serviços Gerais e Manutenção; Material e Patrimônio; e Finanças e Contratos), em atividade no período descrito acima, somando-se um universo de 17 gestores.

\begin{tabular}{|c|c|}
\hline $\begin{array}{l}\text { Capacidades Centrais da } \\
\text { Aprendizagem }\end{array}$ & Variáveis \\
\hline \multicolumn{2}{|r|}{ Domínio Pessoal } \\
\hline Estimular as aspirações & \multirow{2}{*}{ Competências (viver em estado de aprendizagem contínua) } \\
\hline Desenvolver conversas reflexivas & \\
\hline Estimular as aspirações & \multirow{2}{*}{ Metas Individuais (conhecimento de si mesmo) } \\
\hline Desenvolver conversas reflexivas & \\
\hline \multicolumn{2}{|r|}{ Modelos Mentais } \\
\hline Desenvolver conversas reflexivas & \multirow{2}{*}{$\begin{array}{c}\text { Reflexão e Diálogo (sobre ideias profundamente arraigadas, generalizações } \\
\text { ou imagens que influenciam nosso modo de encarar o mundo e nossas } \\
\text { atitudes) }\end{array}$} \\
\hline Estimular as aspirações & \\
\hline Entender a complexidade & \multirow{2}{*}{$\begin{array}{l}\text { Inovação (todos os modelos mentais precisam ser analisados e testados para } \\
\text { que seja escolhido o melhor modelo mental para a resolução dos problemas) }\end{array}$} \\
\hline Entender a complexidade & \\
\hline \multicolumn{2}{|r|}{ Visão compartilhada } \\
\hline Estimular as aspirações & \multirow{2}{*}{$\begin{array}{l}\text { Estratégias (as organizações devem ter objetivos, valores e missão que se } \\
\text { tornem compartilhados) }\end{array}$} \\
\hline Desenvolver conversas reflexivas & \\
\hline Desenvolver conversas reflexivas & \multirow{2}{*}{$\begin{array}{l}\text { Comunicação Interna (a visão compartilhada proporciona o foco e energia } \\
\text { para a aprendizagem) }\end{array}$} \\
\hline Entender a complexidade & \\
\hline \multicolumn{2}{|r|}{ Aprendizagem em equipe } \\
\hline Entender a complexidade & \multirow{2}{*}{$\begin{array}{l}\text { Habilidade em Equipe (equipes de aprendizagem devem saber se } \\
\text { movimentar entre o diálogo e a discussão) }\end{array}$} \\
\hline Entender a complexidade & \\
\hline Desenvolver conversas reflexivas & \multirow{2}{*}{$\begin{array}{l}\text { Disseminação do Conhecimento (o aprendizado em grupo é uma disciplina } \\
\text { coletiva) }\end{array}$} \\
\hline Estimular as aspirações & \\
\hline \multicolumn{2}{|r|}{ Pensamento sistêmico } \\
\hline Desenvolver conversas reflexivas & \multirow{2}{*}{$\begin{array}{l}\text { Aprendizagem (o todo deve ser analisado, planejado e a organização deve } \\
\text { levar em consideração as consequências de suas decisões) }\end{array}$} \\
\hline Entender a complexidade & \\
\hline Estimular as aspirações & \multirow{2}{*}{$\begin{array}{l}\text { Competência Interdisciplinar (a organização é composta por partes que se } \\
\text { unem como sistemas) }\end{array}$} \\
\hline Entender a complexidade & \\
\hline
\end{tabular}

Quadro 1 - Distribuição das variáveis do questionário por disciplina. Fonte: Elaborado pelos autores.

Os dados obtidos com a aplicação do questionário e com as entrevistas foram analisados em três etapas: 1) a prática dos gestores e sua relação com as disciplinas da organização que aprende; 2) dificuldades encontradas pelos gestores e 3) desenvolvimento organizacional: estratégias aprendentes.

As perguntas do questionário referentes às cinco disciplinas apresentavam quatro possibilidades de resposta. Foram considerados os seguintes valores às respostas: 3 (três), para aquela resposta que mais se aproximava da resposta conceitual; 2 (dois), para aquela que ficava numa posição intermediária; 1 (um), para aquela que mais se distanciava da proposta conceitual; e 0 (zero), para aquela que constava "Nenhuma das Respostas Anteriores".

Esses valores foram definidos utilizando-se como base o conceito de média ponderada (Spiegel, 1985). Para a análise dos dados obtidos nos questionários foi utilizado um intervalo de 
três níveis distintos, sendo: média entre 2,59 e 3,0: a variável mostrou alto grau de concordância com o modelo proposto; média entre 2,28 e 2,58: a variável mostrou médio grau de concordância com o modelo proposto; e, média entre 2,07 e 2,27: a variável mostrou baixo grau de concordância com o modelo proposto. O tratamento dos dados foi realizado através de planilhas eletrônicas.

A classificação definida foi utilizada também por outros autores (Terra, 2000; Vasconcelos, 2000; Felício Junior, 2002; Buys Gonçalves, 2008), pois consideram que esta facilita a visualização dos pontos que precisam ser melhores trabalhados na instituição pesquisada, na busca de se aproximar do modelo proposto.

\section{DISCUSSÃO DOS RESULTADOS}

\subsection{Caracterização dos respondentes}

A maioria dos gestores respondentes da pesquisa eram homens com idade menor que 40 anos, com escolaridade em nível superior e com pós-graduação. Além disso, a grande maioria ocupava função de coordenação (em nível tático) e tinham até 3 (três) anos de experiência na função de gestor.

5.2 A prática dos gestores e sua relação com as disciplinas da organização que aprende

A Figura 1 refere-se às variáveis da disciplina Domínio Pessoal, que são "Competências" e "Metas Individuais". (grifo nosso).

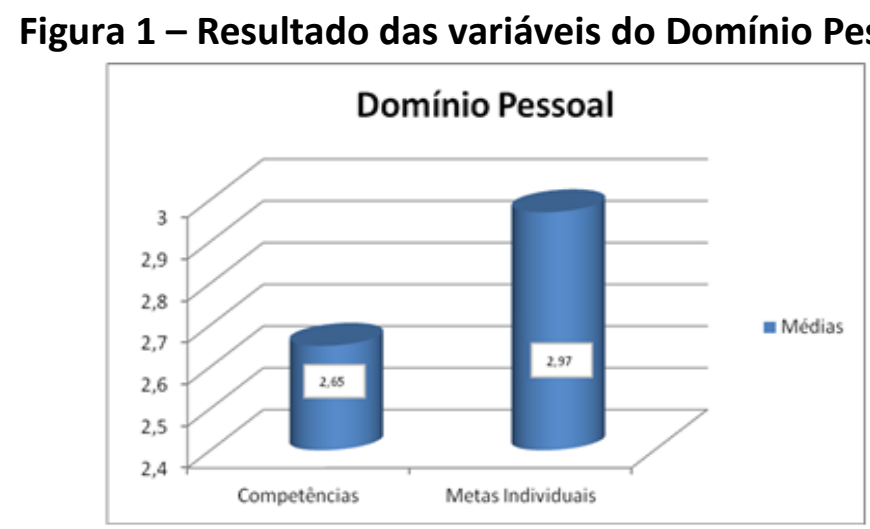

Fonte: Dados da Pesquisa.

A variável "Metas Individuais" que tem como capacidades centrais de aprendizagem estimular as aspirações e desenvolver conversas reflexivas sobre o conhecimento de si mesmo, obteve a maior média entre os gestores respondentes, sendo 2,97, o que representa $99 \%$ do total (média máxima - 3). Esse resultado sugere que uma maioria significativa dos gestores, possui autocontrole emocional quando precisam tomar decisões de nível arriscado que implicarão no futuro da organização que atuam, para tanto, procuram decidir conjuntamente com a equipe de trabalho, e isso os ajuda a lidar com os impulsos provocados pelos imprevistos ocasionados com as constantes mudanças no complexo contexto organizacional; ao invés de agirem constantemente apagando incêndios e deixando que os acontecimentos determinem suas ações (Lück, 2000). 
Significa ainda que os gestores respondentes tem uma percepção clara da realidade e firmeza dos seus propósitos. Segundo Senge (2012), o domínio pessoal das metas individuais é o conhecimento de si mesmo, que vai muito além das habilidades e das competências, trata-se de conhecer a si mesmo e seus limites.

Com relação à variável "Competências", têm as mesmas capacidades centrais da variável anterior sobre viver em estado de aprendizagem contínua. A média desta variável foi de 2,65 , que representa $88,33 \%$ do total. Desse modo, os gestores sabem que mesmo estando bem qualificados para o cargo, pois alguns possuem até mesmo o nível de doutorado na área em que atuam $(23,5 \%)$, precisam se aperfeiçoar e contribuir mais como gestores para construção do processo de aprendizagem organizacional contínuo de modo que se constitua numa cultura interna, capaz de adquirir, criar, produzir novos insights, transferir conhecimentos e modificar o comportamento de seus membros. (Senge, 2012).

Os resultados para essa variável corroboram os obtidos por Felício Junior (2002) que encontrou $81,50 \%$. Segundo o autor, esse é um resultado bastante animador, devido às transformações rápidas e constantes que hoje determinam o mundo de trabalho e dos negócios e que fazem com que as instituições de ensino superior precisem desenvolver um ambiente propício à criatividade de forma a disseminar a cultura aprendente.

Para Buys Gonçalves (2008), que em pesquisa também encontrou média positiva para essa variável $(79,20 \%)$, esse resultado sugere que grande parte dos trabalhadores pesquisados considera-se criativo e competente, procurando continuamente expandir suas capacidades e habilidades individuais em prol da aprendizagem organizacional.

A média geral das variáveis da disciplina Domínio Pessoal foi de 2,81 , que representa 93,67\% próximas ao modelo proposto. Desse modo, as variáveis definidas para a primeira disciplina se adequaram em Alto Grau de Concordância com a proposta conceitual do modelo da Quinta Disciplina. Portanto, quanto ao Domínio Pessoal, a instituição pesquisada foi considerada como uma instituição compatível com uma Organização que Aprende na perspectiva defendida por Peter Senge (2012).

A Figura 2 representa os dados obtidos para as variáveis da disciplina Modelos Mentais. (grifo nosso). Nesse sentido, a variável "Reflexão e Diálogo" que tem como capacidades centrais de aprendizagem estimular as aspirações e desenvolver conversas reflexivas sobre ideias profundamente arraigadas, generalizações ou imagens que influenciam nosso modo de encarar o mundo e nossas atitudes, obtiveram a maior média, sendo 2,53, que representa $84,33 \%$ do total. Esse resultado significa que os gestores não se limitam às próprias ideias e valores para decidirem, e aceitam as opiniões dos outros, mesmo que vão de encontro com as deles.

Figura 2 - Resultado das variáveis dos Modelos Mentais.

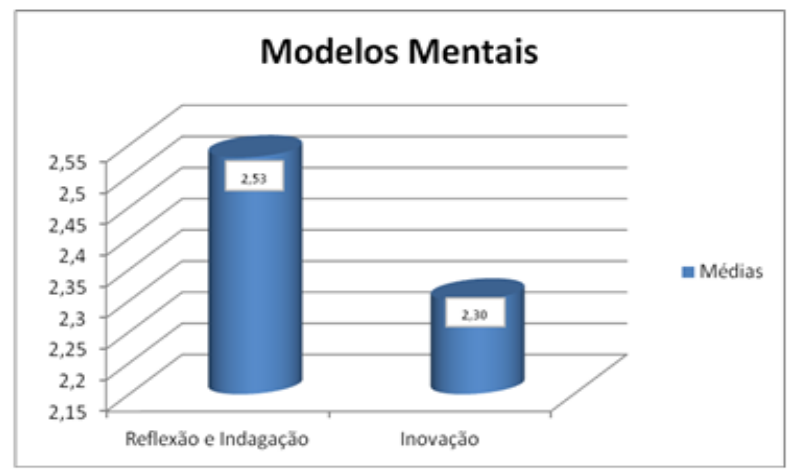

Fonte: Dados da Pesquisa. 
Nesse sentido, a possibilidade da existência de modelos mentais múltiplos proporciona múltiplas perspectivas, ou seja, vários modelos mentais ajudam a criar o que Nonaka e Takeuchi (1997) chamaram de "Flutuação e Caos Criativo", que se refere a capacidade de reconsiderar sempre nosso pensamento e perspectivas fundamentais, a partir da reflexão e do diálogo, que induz e fortalece o compromisso subjetivo dos indivíduos com a organização, desenvolvendo inclusive novos valores (Boog, 2004). Esse fortalecimento do compromisso se dá através do domínio pessoal.

Nesse sentido, o importante é que o caos criativo propicie a quebra de paradigmas, revoando-se os conceitos arraigados, de modo que os gestores estejam propensos aos novos modelos da aprendizagem organizacional. (Senge, 2012).

Os resultados obtidos por Felício Junior (2002) demonstraram essa variável como a maior média entre os respondentes, $82 \%$ do total. 0 autor argumenta que esse resultado demonstra que a maioria das pessoas que participaram da pesquisa, consideram que a referida instituição proporciona condições e incentiva reflexão e indagação, o que resulta, segundo o autor, em mudanças de valores, atitudes e comportamentos pessoais.

A média encontrada para a variável "Inovação" que tem como capacidade central de aprendizagem entender a complexidade sobre que os modelos mentais precisam ser analisados e testados para que seja escolhido o melhor deles para a resolução dos problemas, foi de 2,30, que representa 76,67\% do total. Esse resultado sugere que os gestores reconhecem a necessidade de inovação no trabalho, inclusive quando essa mudança significa trocar a equipe que o gestor já estava acostumado a trabalhar. Nesse contexto, Senge (2012) ratifica que a manutenção dos modelos mentais pode congelar organizações e setores em práticas obsoletas, e impedir a aprendizagem, entretanto, também afirma que a superação desses modelos mentais podem contribuir para acelerar a aprendizagem. Do contrário, se os modelos mentais não forem considerados para inovação, o pensamento sistêmico perde grande parte de sua potência. (Senge, 2012).

A média geral das variáveis dos Modelos Mentais foi de 2,41, que representa $80,33 \%$ próximas ao modelo proposto. Desse modo, as variáveis definidas para a segunda disciplina se adequaram em Médio Grau de Concordância com a proposta conceitual de Senge (2012). Portanto, quanto aos Modelos Mentais, a instituição pesquisada foi considerada como uma instituição compatível com uma OA.

Com a visualização da Figura 3, observam-se as variáveis da disciplina da Visão Compartilhada, que são "Estratégia" e "Comunicação Interna". (grifo nosso).

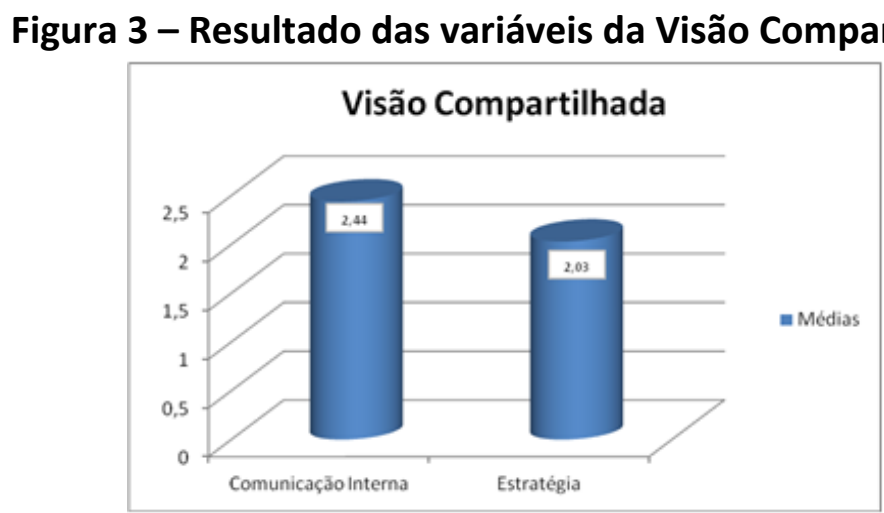

Fonte: Dados da Pesquisa. 
Quanto a variável "Comunicação Interna" que tem como capacidades centrais de aprendizagem estimular as aspirações e desenvolver conversas reflexivas sobre uma visão compartilhada que proporciona o foco e energia para a aprendizagem, obteve a maior média sendo 2,44 , que representa $81,33 \%$ do total. Por outro lado, a variável "Estratégia" que trata que as organizações devem ter objetivos, valores e missão que se tornem compartilhados, obteve média 2,03, que representa $67,67 \%$ do total. Portanto, existe um desequilíbrio evidente entre 0 resultado das variáveis da disciplina visão compartilhada, o que faz com que essa disciplina tenha sido classificada como a segunda pior entre as disciplinas analisadas, apresentando uma média geral de 2,24 na disciplina Visão Compartilhada.

Significa que o objetivo institucional pode não estar sendo comunicado e assumindo com o mesmo grau de importância entre as pessoas, bem como a visão compartilhada da instituição pesquisada não está fornecendo o foco e energia necessários para a aprendizagem em equipe. (Senge, 2012).

O resultado da variável Comunicação Interna sugere que os gestores apesar de afirmarem que compartilham as informações, podem não fazê-lo de modo correto, ou eles acham que compartilham, mas não o fazem. Pode significa ainda, que os respondentes não são estimulados pelos seus gestores a sentirem vontade de possuir uma visão conjunta, baseada no todo da organização. (Senge, 2012).

Desse modo, os Modelos Mentais podem estar afetando essa disciplina, pois conforme afirma Senge (2012), os modelos mentais determinam não apenas como entendemos o mundo, mas também como agimos. Embora os gestores não se comportem (sempre) de forma coerente com suas teorias esposadas (aquilo que dizem), as pessoas comportam-se sempre de forma coerente com suas teorias em uso (seus modelos mentais).

Esse resultado pode representar um motivo para o valor da média obtida pela disciplina Modelos Mentais ter sido enquadrada como de médio grau de adequação ao modelo proposto, ou seja, os modelos mentais poderiam atrapalhar o desempenho dessa disciplina, pois segundo Senge (2012) as quatro disciplinas, mesmo que apresentadas de forma separada, são essenciais para o desenvolvimento umas das outras.

Em entrevista, alguns dos gestores afirmaram existir falhas na comunicação interna quando perguntados sobre: "Quais são as dificuldades encontradas na concretização de suas atividades?". Conforme a resposta dos gestores tem-se:

"Os ruídos na comunicação, ou seja, quando algum dos elementos que podem tornar a comunicação efetiva falha, atrapalhando o processo fechar o ciclo que o constitui. Em outras palavras, a não comunicação decorrente do fato de os demais gestores e servidores não terem ainda absorvido a diferenciada noção e conceito de informação e notícia, o que gera conflitos de interesses e cortes a linha comunicacional." (A. A. A.)

"Primeiramente, a falta de padronização dos processos nas secretarias acadêmicas da instituição;

em segundo, a falha na comunicação entre os setores que gerenciam a secretaria de fora do Campus." (B. B. B.)

"...A troca de horário frequente entre docentes e quando não avisam ao setor é algo que dificulta muito nosso trabalho." (C. C. C.)

Desse modo, percebe-se claramente nas falas dos gestores que existem problemas no que concerne à comunicação Interna, o que contribuiu para o baixo desempenho da disciplina da Visão Compartilhada na instituição pesquisada. 
Significa também que a organização pode não está comunicando suas estratégias como uma visão a ser compartilhada, ou um objetivo comum a todos, pois é vital para as organizações em contínuo aprendizado proporcionar o foco e a energia para a aprendizagem. Além disso, compromete a disseminação do conhecimento tácito, que é o conhecimento pessoal incorporado à experiências de trabalho, às habilidades, expertises, envolve fatores intangíveis como crenças, valores, objetivos pessoais, conclusões, insights, feeling, palpites subjetivos, emoções, ideais, competências, raciocínio, modelos mentais, conclusões, gerações de idéias, opiniões, intuição, criatividade etc. (Nonaka \& Takeuchi, 1997; Figueiredo, 2005; Brito, 2005, 2008; Angeloni et al., 2008; King, 2009; Tavares, 2010; Scoot, 2011).

No contexto organizacional, portanto, o resultado das variáveis desta disciplina também pode significar que não existem condições facilitadoras para a criação e socialização do conhecimento tácito, pois importante é que "o conhecimento tácito precisa se tornar explícito; o que não foi dito, precisa ser dito em voz alta; caso contrário, não pode ser examinado, aperfeiçoado ou compartilhado." (Stewart, 1998, p. 66). Pois, "grande parte do capital intelectual consiste em conhecimento tácito, não expresso - como, por exemplo, o conhecimento especializado e os relacionamentos que um vendedor constrói ao longo de anos de trabalho em um território." (Stewart, 1998, p. 62).

Nesse sentido, é importante ter "papéis de gestão do conhecimento". (Skerlavaj et al., 2010; Scoot, 2010; Rakhsh \& Ahmadi, 2011; Shehzad \& Khan, 2013; Wahyuningsih \& Astuti, 2013).

Resultado similar também foi identificado por Felício Junior (2002); Felício e Vasconcelos (2000) e Gonçalves (2008).

No que concerne a variável "Estratégia", o resultado foi ainda menor, sendo 2,03, que representa $67,67 \%$ do total. Percebemos que não existe equilíbrio entre as variáveis dessa disciplina. Esse resultado sugere que quando os gestores precisam decidir em equipe, eles podem não estar compartilhando uma mesma visão e isso dificulta na unidade na hora de escolher a melhor decisão.

Nesse sentido, Senge (2012) defende que ter uma visão compartilhada significa que o objetivo institucional assume o mesmo grau de importância entre as pessoas, e existe um comprometimento tácito em cumpri-lo, quando é comunicado para todos.

A média das variáveis da Visão Compartilhada foi de 2,24, que representa $74,67 \%$ próximas ao modelo proposto. Desse modo, as variáveis representativas da terceira disciplina se adequaram em Baixo Grau de Concordância com a proposta Conceitual. Portanto, quanto à Visão Compartilhada, a instituição pesquisada é considerada como pouco compatível com uma OA na perspectiva defendida por Senge (2012).

Com a visualização da Figura 4, observam-se as variáveis acerca da disciplina da Aprendizagem em Equipe, que são "Habilidade em Equipe" e "Compartilhamento do Conhecimento". (grifo nosso). 


\section{Figura 4 - Resultado das variáveis da Aprendizagem em Equipe}

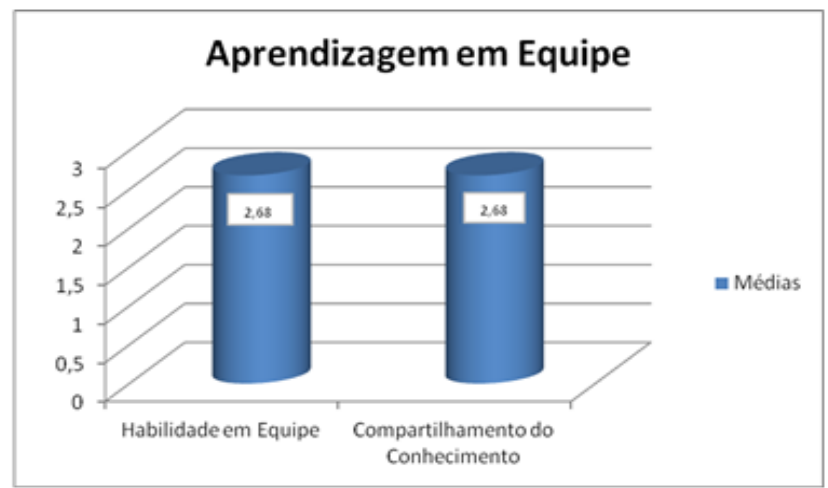

Fonte: Dados da Pesquisa.

A média encontrada para as variáveis dessa disciplina foram iguais, 2,68; o que representa $89,33 \%$ do total. Esse resultado é satisfatório tendo em vista que existe equilíbrio entre as variáveis apresentadas.

No que se refere à variável "Habilidade em Equipe", que tem como capacidade central de aprendizagem entender a complexidade das equipes de aprendizagem de movimentar entre 0 diálogo e a discussão, o resultado sugere que os gestores possuem o hábito de trocar ideias com os demais setores da instituição e não apenas com a equipe da qual são responsáveis, ou seja, pressupõe o alinhamento e desenvolvimento da capacidade da equipe de criar os resultados que seus membros realmente desejam.

Acrescenta-se que, mesmo a aprendizagem em equipe tendo uma média significativa, Senge (2012) adverte que o mundo está repleto de equipes com indivíduos talentosos que compartilham uma visão durante algum tempo, mas que não conseguem sustentar sua aprendizagem. No caso da instituição pesquisada, esse argumento pode ser comprovado, pois mesmo com a média obtida nesta disciplina como favorável; a disciplina Visão Compartilhada não foi tão compatível quanto o esperado com o modelo proposto e significa que a aprendizagem em equipe fica comprometida.

Com relação à variável "Disseminação do Conhecimento", que tem como capacidade central de aprendizagem desenvolver conversas reflexivas e estimular aspirações sobre o aprendizado em grupo como uma disciplina coletiva, o resultado sugere que a maioria dos gestores se consideram comunicativos o que facilita a troca do conhecimento com a equipe, além de demonstrar que costumam sempre aprender uns com os outros. Nesse sentido, Senge (2012) ratifica que equipes são pessoas que precisam umas das outras para agir e estão se tornando a principal unidade de aprendizado na organização, além de afirmar que as atribuições individuais são parte de um todo, mas não fazem por si só com que aprendizagem aconteça, mas sim a soma dessas atividades é que farão a diferença para a instituição.

A média das variáveis da Aprendizagem em Equipe foi de 2,68 que representa 89,33\% próximas ao modelo proposto. Desse modo, as variáveis representativas da quarta disciplina se adequaram em Alto Grau de Concordância com a proposta Conceitual, em contestação aos resultados encontrados por Felício Junior (2002) e Byus (2008).

Portanto, quanto à Aprendizagem em Equipe, a instituição pesquisada foi considerada como uma instituição muito compatível com uma OA na perspectiva defendida por Senge (2012).

Significa ainda que, a organização pesquisada tem processos de alinhamento e desenvolvimento da capacidade de um grupo criar os resultados que seus membros realmente 
desejam, e isso se desenvolve a partir da criação de um objetivo comum e também do domínio pessoal.

A Figura 5 contém as variáveis "Aprendizagem" e "Competência Interdisciplinar", que contemplam a Quinta Disciplina, o Pensamento Sistêmico. (grifo nosso).

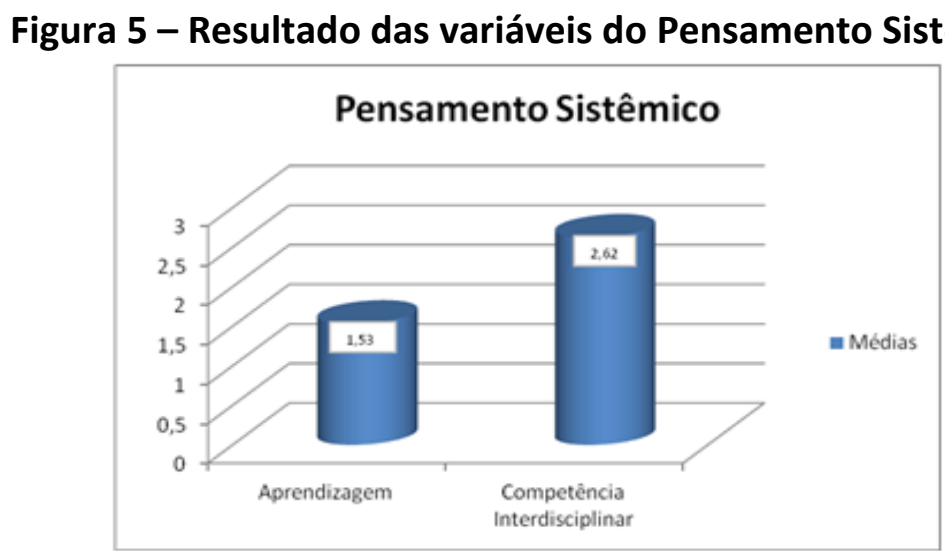

Fonte: Dados da Pesquisa.

A média para as variáveis da Quinta Disciplina foi a mais baixa de todas, 2,07, que representa $69 \%$ do total. A variável "Aprendizagem" que tem como capacidade central de aprendizagem desenvolver conversas reflexivas e entender a complexidade sobre que o todo deve ser analisado, planejado e a organização deve levar em consideração as consequências de suas decisões, obteve média de 1,53. Esse resultado demonstra que a instituição pesquisa não possui uma cultura única que estimula a aprendizagem, pois as pessoas podem não estar preocupadas em analisar todo o contexto em que os problemas organizacionais estão inseridos para que possam desenvolver soluções realmente eficazes e de forma contínua, através da criação do conhecimento e da inovação. (Senge, 2012).

Com relação à variável "Competência Interdisciplinar", que tem como capacidade central de aprendizagem estimular aspirações e entender a complexidade sobre que as organizações são compostas por partes que se unem como sistemas, a média obtida foi 2,62, que representa $87,33 \%$. Esse resultado, significa que os gestores estão sempre disponíveis a contribuir com os demais setores, independentemente de serem solicitados e ainda que na Instituição a maioria contribui com a concretização dos objetivos organizacionais.

A média das variáveis do Pensamento Sistêmico foi de 2,07; que representa $69,00 \%$ próximas ao modelo proposto. Desse modo, as variáveis representativas da Quinta Disciplina se adequaram em Baixo Grau de Concordância com a proposta Conceitual. Portanto, quanto ao Pensamento sistêmico, a organização foi considerada como pouco compatível com uma OA na perspectiva defendida por Senge (2012).

Esse resultado para a Quinta Disciplina pode ser explicado devido a falta de equilíbrio entre as demais disciplinas. Segundo Senge (2012), essa é a disciplina fundamental que une todas as outras, é o ponto principal da Organização que Aprende. É a disciplina onde se buscar ver o todo em vez das partes, e considerar as pessoas como participantes ativas que influenciam na própria realidade, deixando o presente para se dedicar ao futuro.

Significa ainda que nem tudo que é realizado na organização leva em consideração suas consequências, por exemplo que o trabalho de um pode afetar o do outro, pois a organização é composta por partes que se unem como sistemas e os problemas de hoje podem vir das soluções do passado. Além disso, significa que é preciso "uma mudança de mentalidade" dos gestores 
para que todas as decisões sejam bem planejadas, para que o todo seja analisado e para que os gestores considerem suas consequências. (Senge, 2012).

A seguir a Figura 6 demonstra a síntese contendo o resultado geral por disciplina.

Figura 6 - Resultado Geral das disciplinas do modelo, aplicado ao IFRN- SPP.

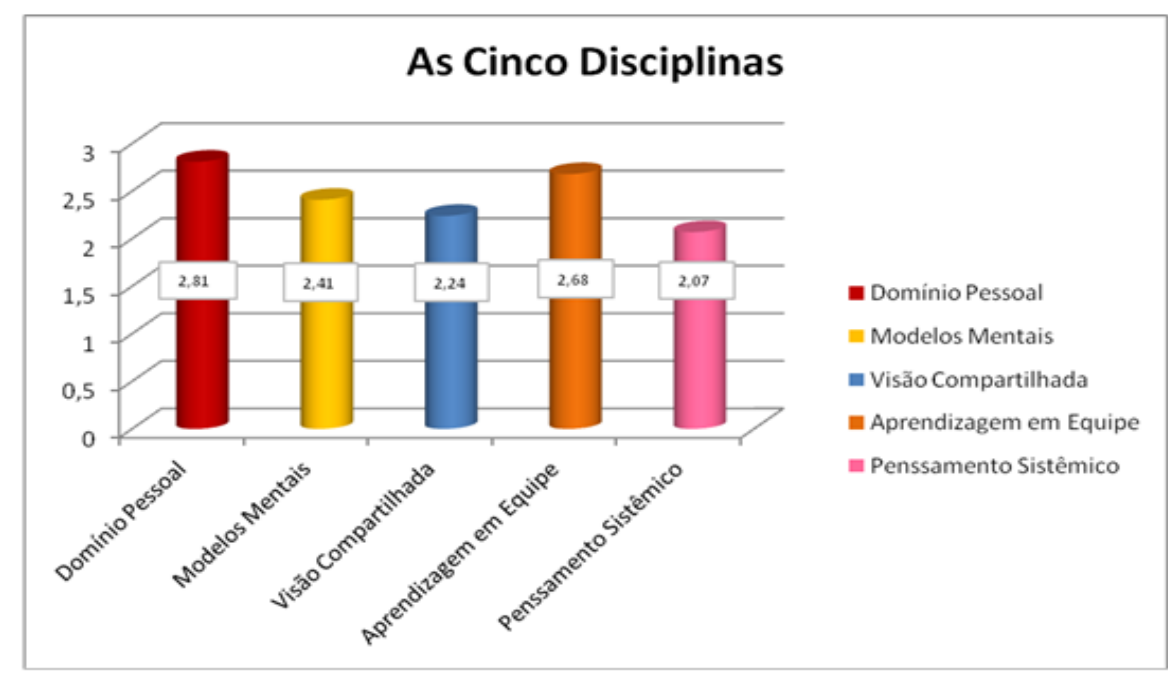

Fonte: Dados da pesquisa (2014).

Conforme se observa na Figura 6, a menor média encontrada foi 2,07 (69,00\%); enquanto a maior foi $2,81(93,67 \%)$, num total de 3,0 (100\%). A seguir tabela contendo resumo por disciplina e por grau de concordância.

\begin{tabular}{|l|l|l|l|}
\hline \multicolumn{1}{|c|}{ Valor Mínimo } & \multicolumn{1}{|c|}{ Valor Máximo } & \multicolumn{1}{|c|}{ Grau de Concordância } & \multicolumn{1}{c|}{ Disciplinas } \\
\hline 2,07 & 2,27 & Baixo & Visão Compartilhada e Pensamento Sistêmico \\
\hline 2,28 & 2,58 & Médio & Modelos Mentais \\
\hline 2,59 & 3,0 & Alto & Domínio Pessoal e Aprendizagem em Equipe \\
\hline
\end{tabular}

Tabela 1 - Representação das disciplinas por grau de concordância. Fonte: Dados da Pesquisa.

Assim, uma vez que duas disciplinas (Visão Compartilhada e a Quinta Disciplina) obtiveram baixo grau de concordância com o modelo e uma médio grau de concordância (Modelos Mentais), ocorre um desequilíbrio que atualmente enquadra a instituição de Educação, Ciência e Tecnologia do Nordeste do Brasil como ainda não totalmente capacitada como uma OA.

Porém, existem duas disciplinas (Domínio Pessoal e Aprendizagem em Equipe) que obtiveram Alto grau de concordância e podem caracterizar a organização como uma OA em potencial para a construção de um perfil aprendente.

\section{CONSIDERAÇÕES PROVISÓRIAS}

A partir dos objetivos da pesquisa, se percebeu que na organização estudada as práticas dos gestores não estão plenamente de acordo com o modelo proposto, pois foram identificados alguns desequilíbrios entre as cinco disciplinas, sobretudo, a Quinta Disciplina que apresentou o pior desempenho, seguida da disciplina da Visão Compartilhada, representando que são disciplinas ainda não totalmente aprendidas e praticadas.

De forma geral, como a organização pesquisada atua com ensino, pesquisa, extensão e gestão, que contemplam processos de aprendizagem em equipe, tanto em nível individual como 
organizacional e para seus beneficiários, esperava-se encontrar nos resultados da pesquisa um desempenho aceitável em todas as disciplinas do modelo proposto por Peter Senge, principalmente quanto a Visão Sistêmica. Entretanto, esta última foi disciplina que apresentou o menor Grau de concordância com o modelo proposto, e pode significar que ao invés de uma visão persuasiva, a organização tem uma visão tímida sobre as possibilidades de criação, aquisição, compartilhamento e transferência do conhecimento em seu interior, pois de forma consciente não consideram as partes como componentes de um todo, não encorajam que as pessoas tenham autoconfiança, que vão além das suas crenças, dos seus impulsos; não possibilitam que seus integrantes compartilhem seus objetivos e trabalhem em equipe em torno de projetos inovadores.

Entretanto, como existiram duas disciplinas com Alto Grau de concordância e uma com Médio Grau de concordância, sendo respectivamente: Domínio Pessoal, Aprendizagem em Equipe e Modelos Mentais, caso o tema seja bem trabalhado na instituição, o desempenho das disciplinas que apresentaram resultados desfavoráveis poderá ser aperfeiçoado e terá chances de tornar a instituição uma organização que aprende conforme o modelo de Peter Senge.

Portanto, a contribuição desta pesquisa para a organização e para a literatura, se dá quando são apontadas as disciplinas com suas características que apresentaram Baixo Grau de adequação ao modelo proposto por Senge (2012), bem como as variáveis que precisam ser desenvolvidas para que a organização incentive a inovação contínua, sendo: vencer a letargia conceitual sobre o modelo de modo que a organização possa se apoderar de seus benefícios e para entender o que é a aprendizagem e saber como realizá-la; considerar mais como fonte de valor as experiências, a criatividade e as ideias dos trabalhadores; criar novos cargos como o de gestor do conhecimento, ativista do conhecimento ou gerente do conhecimento para aperfeiçoar uma visão compartilhada do todo; recompensar os trabalhadores conforme a capacidade de contribuição e lealdade; formalizar um modelo de OA para que as práticas de aprendizagem desenvolvidas façam parte da estratégia organizacional; vencer as atitudes imediatistas que apenas resolvem o problema momentaneamente e comunicar/conectar ao todo as partes.

Para futuras pesquisa, sugere-se a abordagem da temática por meio de epistemologias críticas capazes de compreender o porquê dos resultados encontrados e qual o significado dos mesmos para a cultura da organização estudada e para a sociedade.

\section{REFERÊNCIAS}

Angeloni, M. T. et al. (2008). Gestão do conhecimento no Brasil: casos, experiências e práticas de empresas privadas. Rio de Janeiro: Qualitymark.

Antonello, C. S., \& Godoy, A. S. (2009). Uma agenda brasileira para os estudos em aprendizagem organizacional. Administração de Empresas, São Paulo, 49(3), 266-281, jul/set.

Argyris, C. (1991). Teaching smart people how to learn. Harvard Business Review, 69(3), 99-109, may-jun.

Batista, F. F. (2012). Modelo de Gestão do Conhecimento para a Administração Pública Brasileira: como implementar a gestão do conhecimento para produzir resultados em benefício do cidadão. Brasília: Ipea.

Bolson, S. B. (2012). Gestão do conhecimento: estudo em uma instituição de ensino superior tecnológico. Dissertação de Mestrado Profissional em Administração, Universidade Potiguar, Natal, RN, Brasil.

Boog, Gustavo G. O. (2004). Desafio da competência: Como enfrentar as dificuldades do presente e prepara-se para o futuro. [S.I]: Best Seller. 
Boyatizis, R. (1982). The competent manager: A model of effective performance. New York: Wiley.

Boxenbaum, E., \& Rouleau, L. (2011). New knowledge products as bricolage: metaphors and scripts in organizational theory. Academy of Managament Review, 36(2), 272-296.

Bukowitz, W. R., \& Williams, R. L. (2002). Manual de Gestão do Conhecimento: ferramentas e técnicas que criam valor para a empresa. São Paulo: Bookman.

Buys Gonçalves, F. (2007). Organização de aprendizagem com ênfase na conectividade das pessoas: estudo de caso. Dissertação de Mestrado Profissional em Sistemas de Gestão, Universidade Federal Fluminense / LATEC, Niterói, RJ, Brasil.

Brito, L. M. P. (2005). Gestão de competências, gestão do conhecimento e organizações de aprendizagem: instrumentos de apropriação pelo capital do saber do trabalhador. Fortaleza: Imprensa Universitária.

Brito, L. M. P. et al. (2008). Práticas de pesquisa em gestão de pessoas 2: a tênue separação entre o público e o privado no Brasil. Fortaleza: Edições UFC.

Brito, L. M. P., Oliveira, P. W. S. de, \& Castro, A. B. C. de (2012). Gestão do Conhecimento numa Instituição Pública de Assistência Técnica e Extensão Rural do Nordeste do Brasil. Revista de Administração Pública, 46 (5), 1341-1366, Rio de Janeiro: Fundação Getúlio Vargas.

Castro, A. B. C. de, Brito, L. M. P., \& Varela, J. H. de S. (2014). Quem dissemina saber aprende com o conhecimento que constrói? um estudo de múltiplos casos em organizações públicas do Nordeste do Brasil. Perspectivas em Gestão \& Conhecimento, 4(2), 126-146, jul./dez., João Pessoa, PB, Brasil.

Castro, A. B. C. de, Brito, L. M. P., Santos, R.. S. dos, \& Varela, J. H. de S. (2015). O Planejamento Estratégico como ferramenta para a Gestão Escolar: um estudo de caso em uma instituição de ensino filantrópica da Bahia/BA. Holos, 31(2), 195-2011.

Castro, A. B. C. de, \& Brito, L. M. P. (2016). Gestão do conhecimento: como as organizações públicas do Brasil percebem esse modelo? Gestão Industrial, 12(2), 59-72.

Corley, K. G., \& Gioia, D. A. (2011). Building Theory About Theory Building: what Constitutes a Theoretical Contribution? Academy of Managament Review, 36(1), 12-32.

Costa, I., Vasconcelos, A. C. F. de, \& Candido, G. A. (2009). Diagnóstico de gestão do conhecimento como mecanismo para criação de valor: um estudo exploratório no SEBRAE-PB. Revista Gestão Industrial, 5(2), 80-98.

Choo, C. W. (2003). A Organização do conhecimento: como as organizações usam a informação para criar significado, construir conhecimento e tomar decisões. São Paulo: Senac.

Dantas, A. C. da C., \& Costa, N. M. de L. (Org.) (2012). Projeto Político-Pedagógico do IFRN: uma construção coletiva: documento-base. Instituto Federal de Educação, Ciência e Tecnologia do Rio Grande do Norte. Natal: IFRN Ed.

Davenport, T., \& Prusak, L. (1998). Conhecimento empresarial: como as organizações gerenciam o seu capital intelectual. Rio de Janeiro: Elsevier.

Dihl, W., Holanda, L. M. C. de, \& Francisco, A. C. de (2010). A utilização do método de diagnóstico para a gestão do conhecimento: estudo de caso numa empresa incubada (ALFA). Revista eletrônica FAFIT/FACIC, 1(1), 30-43.

Dutra, J. de S. (Org.) (2002). Gestão por competências. São Paulo: Gente.

Dutra, J. de S. (2004). Competências. São Paulo: Atlas.

Drucker, P. (1990). Aprendizagem Organizacional. São Paulo: Campus.

Felício Junior, J. (2002). Learning Organization numa instituição de ensino superior: uma proposta empreendedora. Dissertação de Mestrado Profissional em Administração, Fundação Educacional de Caratinga, MG, Brasil. 
Figueiredo, S. P. (2005). Gestão do conhecimento: estratégias competitivas para a criação e mobilização do conhecimento na empresa. Rio de Janeiro: Qualitymark.

Fleury, A. C. M., \& Fleury, M. T. L. (2012). Aprendizagem e Inovação Organizacional: As Experiências de Japão, Coréia e Brasil (2a ed.). São Paulo: Atlas.

Frigotto, G. (1999). Educação e Crise do Capitalismo Real. São Paulo: Cortez.

Galvão, A. P. (2012). Gestão do Conhecimento em empresa internacional de energia. Dissertação de Mestrado Profissional em Administração, Universidade Potiguar, Natal, RN, Brasil.

Garvin, D. A., Edmondson, A. C.; \& Gino, F. (2008). Is Yours a Learning Organization? Harvard Business Review, março 2008, 109-116.

Godoy, A.S. (1995). Pesquisa qualitativa - Tipos Fundamentais, Revista de Administração de Empresas, São Paulo, 35(3), mai./jun.

Gonzaga, A. (2014). Gestão do Conhecimento em Multinacional Brasileira de Energia. Dissertação de Mestrado Profissional em Administração, Universidade Potiguar, Natal, RN.

Hamel, G., \& Prahalad, C. K. Competindo pelo Futuro: estratégias inovadoras para obter o controle do seu setor e criar mercados de amanhã. São Paulo: Campus.

Kauark, F, Manhaes, F. C., \& Souza, C. H. M. (2010). Metodologia da Pesquisa: guia práticoItabuna: Via Litterarum.

King, W. R. (2009). Knowledge Management and Organizational Learning. Annals of Information Systems 4. University of Pittsburgh. Recuperado em 15 outubro, 2015, de http://www.uky.edu/ gmswan3/575/KM_and_OL.pdf.

Le Boterf, G. (2003). Desenvolvendo a competência dos profissionais. Porto Alegre: Artmed Editora.

Lück, H. (2000). Gestão Escolar e a Formação de Gestores. Brasília: Ed. Azeredo.

Marques, F. (2015). Gestão de Pessoas: fundamentos e tendências. Brasília: ENAP.

Meister, J. (1999). Educação corporativa: a gestão do capital intelectual através das universidades corporativas. São Paulo: Makron Books.

Nogueira, R. A., \& Odelius, C. C. (2015). Aprendizagem: evolução no contexto das teorias organizacionais. Perspectivas em Gestão \& Conhecimento, 5(1), 3-18, jan./jun., João Pessoa, PB.

Nonaka, I., \& Takeuchi, H. (1997). Criação de conhecimento na empresa: como as empresas japonesas geram a dinâmica da inovação. Rio de Janeiro: Campus.

McClelland, D. (1973). Testing for Competence Rather Than for Intelligence. American Psychologist, January.

Oliveira, D. de P. R. de (2004). Planejamento estratégico. São Paulo: Atlas.

Oliveira, J. A. de (2011). Gestão do Conhecimento: um estudo de caso em um hospital universitário e de ensino. Dissertação de Mestrado Profissional em Administração, Universidade Potiguar, Natal, RN, Brasil.

Perrenoud, P. et al. (2002). As competências para ensinar no século XXI: a formação dos professores e o desafio da avaliação. Porto Alegre: Artmed.

Quinn, R. E. (2003). Competências gerenciais. Rio de Janeiro: Elsevier.

Rakhshr, P., \& Ahmadi, E. (2011). Creativity, organizational learning, and operation. International Conference on Education and Management Technology, 2, Singapore. Procedings... Singapore: IACSIT Press.

Ramos, M. N. (2001). A Pedagogia das Competências: Autonomia ou Adaptação? São Paulo: Cortez.

Roggero, R. (2003). Qualificação e competência: um diálogo necessário entre sociologia, gestão e educação para alimentar práticas pedagógicas na formação profissional. SENAC. 
Ruas, R., Antonello, C. S., \& Boff, L. H. (2005). Aprendizagem Organizacional e Competências. Porto Alegre: Bookman.

Santos, I. C. (2014). Gestão do Conhecimento: um estudo comparativo entre organizações do Nordeste brasileiro. Dissertação de Mestrado Profissional em Administração. Universidade Potiguar, Natal, RN, Brasil.

Senge, P. R. (1995). A Quinta Disciplina: caderno de campo. Rio de Janeiro: Qualitymark.

Senge, P. R. (2012). A quinta Disciplina: arte e prática da organização que Aprende. São Paulo: Best Seller.

Silva, R. J. A., Sicsú, A. B., \& Crisóstomo, A. P. (2009). Identificação de processos de conhecimento: estudo multicaso em APL de calçados de campina grande. Gestão Industrial, 5(1), 189-215, Campus Ponta Grossa - Paraná, PR, Brasil.

Schlesinger, C. C. B., Reis, D. R. dos, Silva, H. de F. N., Carvalho, H. G. de, Sus, J. A. L. de, Ferrari, J. V., Skrobot, L. C., \& Xavier, S. A. de P. (2008). Gestão do Conhecimento na Administração Pública. Instituto Municipal de Administração Pública - IMAP.

Scoot, B. B. (2011). Organizational Learning: A Literature Review. Discussion Paper \#2011-02. Queens University, jan. Recuperado em 18 novembro, 2015, de http://irc.queensu.ca/sites/default/files/articles/organizational-learning-a-literature review.pdf.

Shehzad, R., \& Khan, M. N. A. (2013). Integrating Knowledge Management with Business Intelligence Processes for Enhanced Organizational Learning. International Journal of Software Engineering and Its Applications, 7(2), March. Recuperado em 25 novembro, 2015, de http://www.sersc.org/journals/IJSEIA/vol7_no2_2013/7.pdf.

Skerlavaj, M., Song, J. H., \& Lee, Y. (2010). Organizational learning culture, innovative culture and innovations in South Korean firms. Journal Expert Systems with Applications, 37, 6390-6403. Recurepado em 20 novembro, 2015, de http://igup.urfu.ru/docs/Bank\%20English_Transleted\%20Articles/English/Innovation\%20Mana gement/Organizational\%20learning\%20culture,\%20innovative\%20culture\%20and\%20innovati ons\%20in\%20South\%20Korean\%20firms.pdf.

Spiegel, M. (1985). Estatística (2a ed.). São Paulo: Mc Graw-Hill do Brasil.

Stewart, T. A. (1998). Capital Intelectual (4a ed.). Rio de Janeiro: Campus.

Strauhs, F. do R., Pietrovski, E. F., Santos, G. D., Carvalho, H. G. de, Pimenta, R. B., \& Penteado, R. S. (2012). Gestão do Conhecimento nas Organizações. Curitiba: Aymará Educação.

Sveiby, K. E. (1998). A nova riqueza das organizações, gerenciando e avaliando patrimônios de Conhecimento. Rio de Janeiro: Campus.

Takahashi, A. R. W., \& Fischer, A. L. (2009). Debates passados, presentes e futuros da aprendizagem organizacional - um estudo comparativo entre a produção acadêmica nacional e internacional. Administração Mackenzie, 10(5), São Paulo, SP, Brasil.

Tavares, W. R. (2010). Gestão do conhecimento: Educação e Sociedade do Conhecimento. São Paulo: Ícone.

Terra, J. C. C. (2000). Gestão do Conhecimento: o grande desafio empresarial uma abordagem baseada na aprendizagem e na criatividade. São Paulo: Negócio Editora.

Terra, J. C. C. (2005). Gestão do conhecimento: o grande desafio empresarial. Rio de Janeiro: Elsevier.

Tsang, E. W. K. (1997). Organizational learning and the learning organization: a dichotomy between descriptive and prescriptive reasearch. Human Relations, 50(1), 73-89, New York. 
Vasconcelos, S. R. V. (2014). Gestão do conhecimento em cooperativa médica do norte/nordeste brasileiro. Dissertação de Mestrado Profissional em Administração. Universidade Potiguar, Natal, RN, Brasil.

Vasconcelos, M. C. R. L. (2000). Cooperação Universidade/Empresa na Pós-Graduação: contribuição para a aprendizagem, a Gestão do Conhecimento e a Inovação na Indústria Mineira. Tese de Doutorado. Universidade Federal de Minas Gerais, Belo Horizonte, MG, Brasil.

Vergara, S. C. (2007). Projetos e relatórios de pesquisa em administração (11a ed.). São Paulo: Atlas.

Wahyuningsih, A., Astuti, E. S., \& Musadieq, M. A. (2013). The Effect of Organizational Learning on Knowledge Management, Capability and Performance of Organization. Journal of Basic and Applied Scientific Research. 3(5), 159-169.

Yin, R. K. (2005). Estudo de Caso: Planejamento e métodos (3a ed.). Porto Alegre: Bookman.

Zarifian, P. (2001). Objetivo Competência: por uma nova lógica. São Paulo: Atlas. 